\title{
Loss of product (cryogenic liquid) for filling of cars - tanks: production of liquid
}

\author{
Andrea da Silva Torrinha ${ }^{1}$, Maria Socorro Frutuoso de Oliveira ${ }^{1}$, Megue Pinheiro Guedes ${ }^{1}$, Jandecy Cabral Leite ${ }^{2}$ \\ a.torrinha@gmail.com,mariah_nay@hotmail.com,mguedes005@gmail.com,jandec.ycabral@itegam.org.br \\ ${ }^{1}$ Centro Universitário do Norte (UNINORTE). Av. Joaquim Nabuco, 1469, Centro. Manaus-Amazonas-Brasil. CEP: 69005-290. \\ Fone: +55 (92) 32125000. \\ ${ }^{2}$ Instituto de Tecnologia e Educação Galileo da Amazônia (ITEGAM). Avenida Joaquim Nabuco, 1990. Manaus-Amazonas- Brasil. \\ CEP: 69.020-031. Fone: +55(92) 3584 6145/+55 (92) 32482646.
}

\begin{abstract}
The transport of cryogenic products ensues through tank cars occurring product loss during filling thereof, either differential pressure or through cryogenic pump. The aim of the paper is to analyze the means used today for such a task, checking the possible alternatives to be implemented to remedy the problem. The methods and techniques were used in the research field, a questionnaire and existing research subsidies (manuals, reports, procedures). The results were proof of how much this can affect the supply of gas to the Brazilian market, which involved hospitals, universities, clinics and industries are because this segment is heavily involved in the growth of the economy.
\end{abstract}

Keywords: cryogenic liquids, tank cars, filling.

\section{Pérdida de producto (líquido criogénico) para el relleno de coches - tanques: producción de líquidos}

\section{RESUMO}

O transporte de produtos criogênicos através de sucessivas perdas petroleiros produto ocorre durante o preenchimento dos mesmos, seja por diferencial de pressão ou através de bomba criogênica. O objetivo deste artigo é analisar os métodos utilizados atualmente para tal tarefa, verificando as possíveis alternativas a ser tomadas para corrigir o problema. Os métodos e técnicas utilizadas no campo de pesquisa, um questionário e bolsas de investigação existentes (manuais, relatórios, procedimentos). Os resultados são a prova do quanto isso pode afetar o fornecimento de gás para o mercado brasileiro, que envolveu hospitais, universidades, clínicas e indústria são, porque este segmento está fortemente envolvido no crescimento da economia.

Palavras-chave: criogênico, enchimento de carros, tanque de líquido.

\section{INTRODUÇÃO}

A perda dos produtos oxigênio $\left(\mathrm{O}_{2}\right)$ e nitrogênio $\left(\mathrm{N}_{2}\right)$ se dá em alguns momentos do processo de enchimento de carretas quando os líquidos $\mathrm{LO}_{2}$ e $\mathrm{LN}_{2}$ encontram-se a temperaturas baixíssimas (cerca de $-186^{\circ} \mathrm{C}$ para o oxigênio e $-190^{\circ} \mathrm{C}$ para o nitrogênio). Este processo de enchimento provoca o aumento de temperatura destes líquidos, fazendo com que estes evaporem e voltem ao estado de gás. Vários tipos de permutadores de calor têm sido usados em tecnologia criogênica através de seu século mais de uma longa história. Em geral a seleção da geometria depende da aplicação. A decisão deve considerar a pressão de operação, as taxas de fluxo de massa, o dever de calor total, bem 
como, custos de operação e de investimento [2] (BARRON, 2000).

A escolha do tema justifica-se pelo abundante uso dos produtos pela sociedade, o oxigênio em forma de gás, por exemplo, é muito utilizado em hospitais e no processo de fundição de vários metais e o nitrogênio líquido é muito útil para criogenização, resfriamento e inertização em outros processos laboratoriais e fabris. Hoje vasos criogénicas são amplamente utilizados em muitos campos com o rápido desenvolvimento de armazenamento e transporte criogênico, especialmente nas máquinas, na indústria química, eletrônica e áreas de medicina para substituir os cilindros de gás de alta pressão. Desde vazamento de calor é inevitável para recipientes criogênicos de ambiente para o vaso interior, tubo de apoio, bem como o espaço com isolamento térmico, vaporização do líquido criogênico ocorre continuamente. Libertação de calor varia dependendo de muitos fatores, tais como o projeto e o volume dos recipientes, o isolamento térmico, e a temperatura ambiente [2] (KHEMIS, 2004).

A pesquisa contribui para minimizar a perda de produtos no processo de enchimento dos carros-tanques, considerando que uma estimativa precisa da quantidade de líquidos em tanques criogênicos, é importante para a otimização da entrega. Problemática esta relacionada com o comportamento térmico de liquido e de gás no interior do vaso criogênico. Especificamente, aferição de massa no interior de tanques criogênicos [3] (YU, 1976).

Sendo assim, diante do problema apresentado, questionase: $\mathrm{O}$ que fazer para que não ocorra desperdício de gases no processo de enchimento de carros-tanques?

\section{REVISÃO BIBLIOGRÁFICA}

\subsection{A criogenia e sua matéria - prima}

A criogenia trata da produção e dos efeitos decorrentes de temperaturas muito baixas. Esta palavra foi usada pela primeira vez pelo professor Kamerlingh Onnes, da Universidade de Leiden, na Holanda [4] (SCURLOCK, 1993), para o mesmo autor menciona a palavra para se referir a liquefação de gases como oxigênio, nitrogênio, hidrogênio e hélio. $\mathrm{O}$ termo criogenia tem sido usado para falar de temperaturas abaixo de -150 C [5].

Os gases permanentes comuns (oxigênio e nitrogênio) sofre mudança de gás para líquido à pressão atmosférica às temperaturas, o chamado ponto de ebulição normal (NBP). Tais líquidos são conhecidos como líquidos criogênicos ou criogênios [6][7].

A criogenia vem do grego (crio gen) que significa gerar ar frio. Sendo definida, como a produção e utilização intensiva de temperatura baixa ou fria, que é alcançado por gases quando estão na sua forma líquida. Formada precisamente por oxigênio e nitrogênio, a matéria-prima para a criogenia é retirada do ar atmosférico [8][9][10] (TRINDADE, 2003).

\subsection{Perda de produto em $\mathrm{m}^{3}$ e $\mathrm{R} \$$}

Uma das causas de maior perda de produto no processo de liquefação dos gases do ar se dá no processo de enchimento de carros-tanques. Isso acontece devido à mudança de temperaturas durante esta etapa.

Primeiramente os gases do ar se liquefazem a baixíssimas temperaturas e pressões, uma pressão de menos que $1 \mathrm{~atm}$ (pressão atmosférica). Solicitados os produtos pelos clientes, acontece o enchimento dos carros-tanque, estes produtos serão transportados através de tubulações isoladas termicamente, onde a mesma encontra-se com temperaturas mais elevadas que as do produto, com isso o líquido criogênico troca calor com essas estruturas e tende a voltar ao seu estado natural na forma de gás. Da saída do tanque até a entrada da bomba (sucção) de enchimento ocorre um acúmulo de gás que deve ser expurgado, é a chamada "escorva" da bomba, como não existe apenas gás durante este procedimento uma quantidade razoável de líquido criogênico também é desperdiçada. Quando todo gás é retirado da linha de enchimento entre tanque e entrada da bomba dá-se início a transferência do produto até o carro tanque.

Outro ponto relevante é o controle da abertura da saída de vapor do interior do carro-tanque, pois quando o líquido criogênico adentra o tanque horizontal da carreta, também encontra temperaturas mais elevadas e pressões maiores que o fazem voltar ao seu estado gaseificado, e desse modo, a pressão interna do tanque horizontal aumenta exponencialmente chegando ao ponto de ser maior do que a pressão de descarga da bomba de enchimento, ocasionando o desligamento automático desta devido à alta pressão, e para evitar que isto ocorra se faz necessário o alivio de pressão através da abertura de uma válvula específica denominada "vent", porém a abertura desta deve servir de equilíbrio de pressões entre a bomba de enchimento e tanque horizontal da carreta, ou seja, manter um diferencial de pressão ideal para que a bomba não desarme e nem jogue fora produto, uma vez que o liberado através do vent também é produto que se estivesse no interior do tanque da carreta estaria na forma líquida.

Em termos de volume de líquido durante o enchimento observou-se que cerca de $8 \%$ a $10 \%$ do produto que sai do tanque criogênico se perde e que é notado somente quando se faz a pesagem final do carro-tanque já cheio [11]. Segue demonstrativo:

\section{Perdas de produtos $1^{\circ}$ semestre de 2013 - Oxigênio $\left(\mathrm{O}_{2}\right)$ e Nitrogênio $\left(\mathbf{N}_{2}\right)$}

Tabela 1- Perdas em $\mathrm{m}^{3}$ no $1^{\circ}$ semestre de 2013.

\begin{tabular}{|c|c|c|c|c|c|c|}
\hline PERÍODO & JANEIRO & FEVEREIRO & MARÇO & ABRIL & MAIO & JUNHO \\
\hline PERDAS 02 $\left(\mathrm{M}^{3}\right)$ & 63.795 & 63.506 & 28.082 & 70.265 & 84.694 & 71.749 \\
\hline PERDAS N2 (M³) & 96.273 & 71.915 & 65.233 & 81.436 & 81.765 & 79.985 \\
\hline PERDA TOTAL 02 - N2 & 160.068 & 135.421 & 93.315 & 151.701 & 166.459 & 151.734 \\
\hline
\end{tabular}

\subsection{Alternativas para resolução do problema}

Fazendo-se um acompanhamento do problema das perdas em si de produto pode-se notar que elas se dividem em momentos distintos:

- Perdas por troca de calor das tubulações (resfriamento da bomba e partida inicial da bomba) 
- Perdas por aumento da pressão do interior do carrotanque (enchimento).

Para a primeira situação, foi verificado que as temperaturas externas exercem grande influência nas perdas de produto, sendo assim sugere-se que o isolamento térmico existente hoje, possa ter uma eficiência maior, se a sua espessura for aumentada ou se for colocado outro material isolante (térmico), garantindo um mínimo de trocas de calor.

Para o segundo ponto, podemos averiguar que se faz necessário o treinamento mais dirigido ao uso da bomba de enchimento para os responsáveis envolvidos no manuseio da referida bomba para que possam entender melhor seu funcionamento e assim evitar que haja um grande diferencial de pressão desnecessário durante o enchimento das carretas de transporte de produto.

\section{MATERIAIS E MÉTODOS}

$\mathrm{Na}$ apuração de informações para a pesquisa foi inicialmente realizado entrevistas com os funcionários envolvidos com o tema através de uma ficha que constam itens relacionados à problemática. No questionário, funcionários descreveram suas atividades, bem como relataram os problemas em que ocorre a perda de produto. A pesquisa é sempre uma versão de um não saber ou não compreender algo que o pesquisador acha que eles deveriam saber ou entender melhor [12] (TEIXEIRA, 2012).

A importância dessa matéria prima para as empresas que a utilizam se faz relevante a abordagem do assunto, pois o desperdício desses produtos reflete tanto na lucratividade da empresa como no meio ambiente.

A ficha de entrevista desta ação-problema abordando que o profissional vivencia quando executa tal atividade também incentivando para que o mesmo enfatize as suas sugestões para que o problema seja sanado. Outra fonte de dados foi retirada de documentos de controle do processo de enchimento tais como: relatórios de produção, onde estão as planilhas de controle do que foi produzido, da quantidade que tem em estoque, de horas de planta parada, quantidade de saída etc. Para obtenção de dados podem ser utilizados três procedimentos: pesquisas documentais, pesquisa bibliográfica e contato direto [13] (LAKATOS, 2010a).

De acordo com as entrevistas realizadas notou-se nitidamente o quanto os colaboradores estão cientes das perdas existentes tanto na escorva da bomba como também quando o enchimento ocorre, porém não há um questionamento mais aprofundado devido à falta de informações para com estes. Toda pesquisa envolve o levantamento de dados de variadas fontes, quaisquer que sejam os métodos ou técnicas empregadas. Os dois processos pelo quais se podem obter os dados são a documentação direta e a indireta [14] (LAKATOS, 2010b).

\section{RESULTADOS ANÁLISE E DISCUSSÕES}

\subsection{Perfil da empresa}

A WM Gases Industriais Amazônia é uma das maiores empresas de gases industriais e medicinais da América do Sul.
Integra o Polo Industrial de Manaus (PIM) e seu portfólio de produtos inclui gases atmosféricos (oxigênio e nitrogênio), utilizados por indústrias e hospitais, oferecendo produtos com qualidade [15].

\subsection{Levantamentos de dados}

No estudo de caso abordado, verificou-se que após o processo de pré-enchimento dos carros-tanques (pesagem inicial; posicionamento na baia de enchimento; despressurização do carro; conexão das mangueiras de análise e enchimento; purga das mangueiras de enchimento e análise), nota-se uma perda significativa de produto nos seguintes momentos do processo: resfriamento de bomba, partida inicial da bomba e enchimento propriamente dito.

\subsection{Resfriamento da Bomba}

Antes de pôr em funcionamento as bombas centrífugas, é necessário realizar o escorvamento [16][17].

A figura 1A mostra o funcionamento da bomba de enchimento, onde é feita a verificação do material presente no tubo. A figura 1B mostra a primeira perda de produto, pois para ocorrer o resfriamento, se faz necessária a escorva da mesma, ou seja, retirada de gás na tubulação de enchimento.

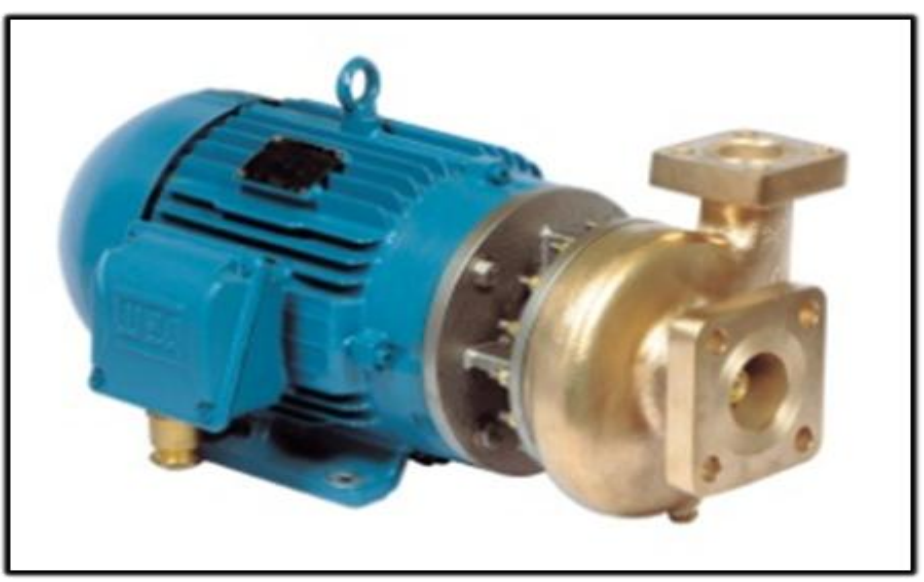

Figura 1A - Bomba Industrial.

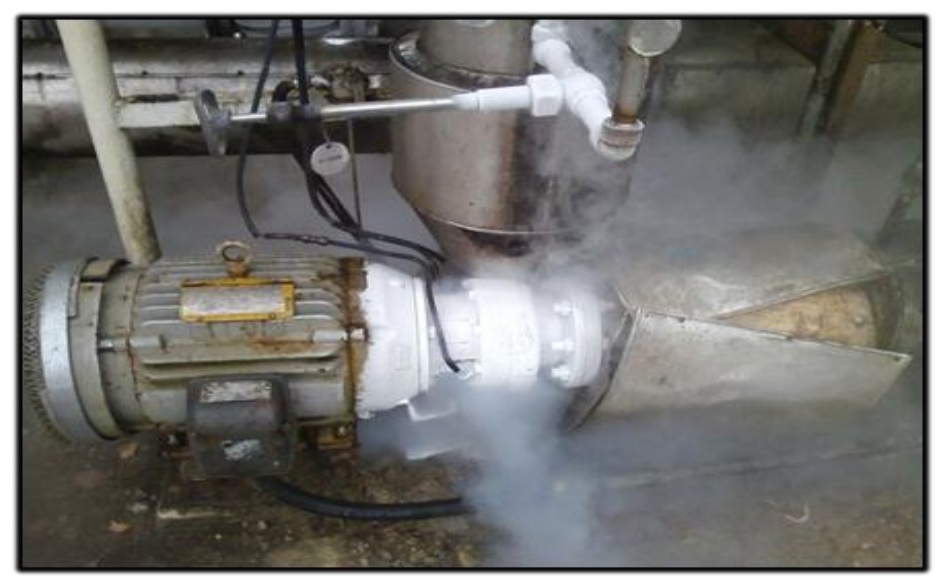

Figura1B - Resfriamento da Bomba. 
Andrea da Silva Torrinha et al./ ITEGAM-JETIA Vol.01, № 02, pp. 04-09. Junho, 2015.

O gás presente nos tubos será expelido do sistema de enchimento (tubulação), através do vaporizador, como exposto na Figura 2. Em virtude de não se poder ter nada além de líquido criogênico em seu interior, uma vez que o referido procedimento é a garantia de abastecimento correto. Utiliza-se produto para realização desta manobra e o mesmo terá esta finalidade até a bomba atingir a temperatura de $-130^{\circ} \mathrm{C}$. Perda aproximadamente de $700 \mathrm{~m}^{3}$ de gás.

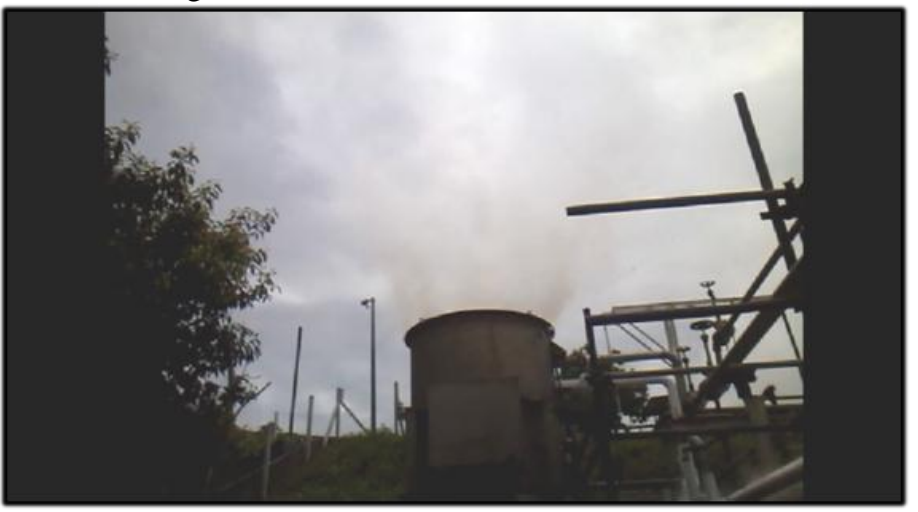

Figura 2. Vaporizador.

\subsection{Partida inicial da bomba}

Para o início do processo de enchimento do carro-tanque é necessário que a pressão esteja abaixo da pressão de descarga da bomba em um diferencial de cerca de $4 \mathrm{~kg}$ entre bomba de enchimento e carro-tanque, com isso uma quantidade razoável de produto se perde, pois é expurgado de dentro do carro-tanque em forma de gás (anteriormente líquido) até que a pressão do interior do carro-tanque esteja com diferencial equilibrado para que a bomba não venha a cair.

\subsection{Enchimento do carro tanque}

A figura 3 mostra que durante o enchimento do carrotanque deve-se liberar a pressão interna do carro através de uma saída de gás denominada "Vent", porém se não for realizado o controle desta pressão ocorre à queda (desligamento) de a bomba devida esta apresentar-se demasiadamente baixa, quebrando assim a escorva anteriormente preparada durante o seu resfriamento.

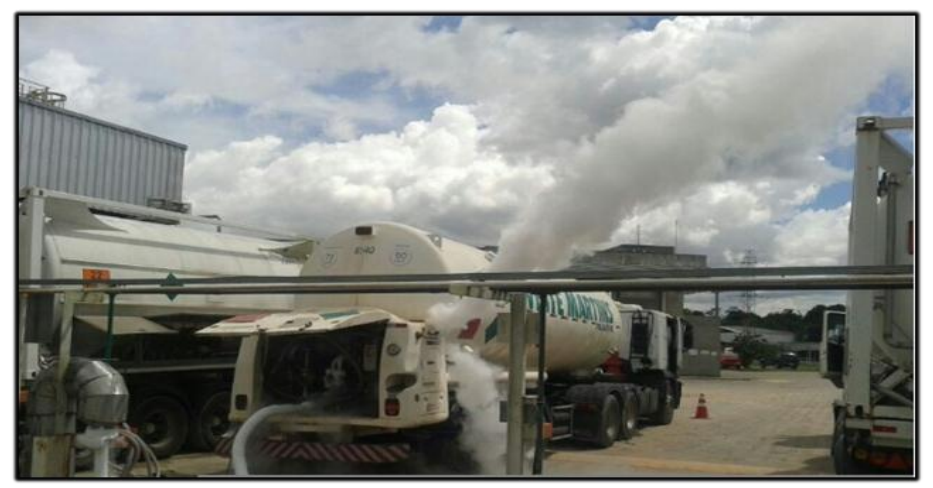

Figura 3. Enchimento de carro-tanque.

\subsection{Análise, resultados e discussões}

Diante da análise dos dados coletados para realização do estudo de caso, verificou-se que existem perdas significativas de produto, onde a empresa em questão deixou de ganhar o valor de $\mathrm{R} \$ 764.876,76$ durante o ano de 2013.Os resultados encontrados estão representados nas Figuras 4, 5, 6, 7, 8 e 9 retratam o quadro de produção dos líquidos oxigênio e nitrogênio, em $\mathrm{M}^{3}$ e em $\mathrm{R}$.

\subsubsection{Comparativo semestral de produção de oxigênio $\left(\mathrm{O}_{2}\right)$ e nitrogênio $\left(\mathrm{N}_{2}\right)$}

O gráfico da figura 4 mostra que no $1^{\circ}$ semestre de 2013 foi produzido o montante equivalente a 5.963,939 $\mathrm{m}^{3}$ dos gases oxigênio $\left(\mathrm{O}_{2}\right)$ e nitrogênio $\left(\mathrm{N}_{2}\right)$. Do total produzido, o gás $\mathrm{O}_{2}$ supera a produção do gás $\mathrm{N}_{2}$ todos os meses do semestre, tendo sua produção total em $3.741,387 \mathrm{~m}^{3}$. A maior produção deste semestre aconteceu no mês de Junho, onde o total produzido por ambos foi de $1.067,409 \mathrm{~m}^{3}$, sendo $720.066 \mathrm{~m}^{3}$, somente de $\mathrm{O}_{2}$.

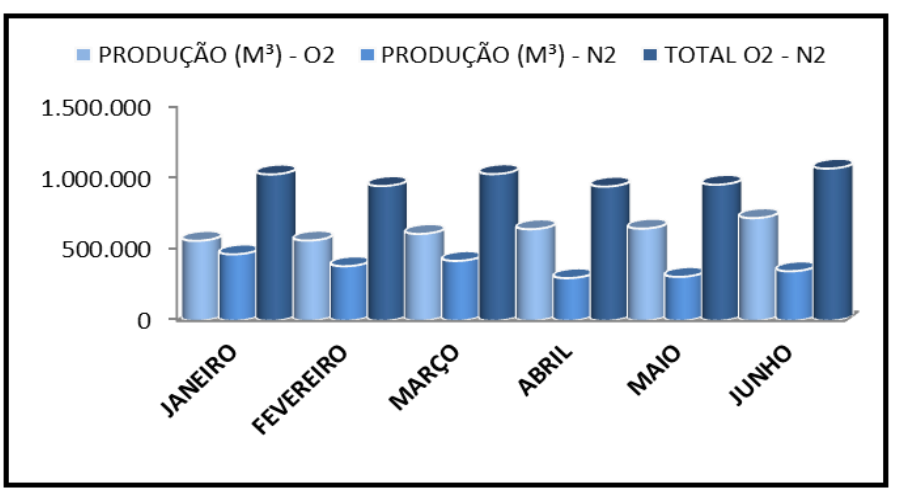

Figura 4. Produção $\mathrm{O}_{2}$ e $\mathrm{N}_{2}$ líquido $\left(\mathrm{m}^{3}\right)$ - $1^{\circ}$ semestre de 2013.

O gráfico da figura 5 mostra no $2^{\circ}$ semestre, a somatória produzida pelos dois gases superou a produção do $1^{\circ}$ semestre, totalizando $6.027,129 \mathrm{~m}^{3}$. É notória também, a permanência de maior produção do $\mathrm{O}_{2}$ sobre o $\mathrm{N}_{2}$, onde verificamos que a produção total de $\mathrm{O}_{2}$ aconteceu no mês de Outubro com 793.092 $\mathrm{m}^{3}$. A maior produção mensal deste semestre se deu no mês de Agosto com 1.192,740 $\mathrm{m}^{3}$ produzidos.

No comparativo semestral, nota-se que a o $2^{\circ}$ semestre foi o período de maior produção de gases.

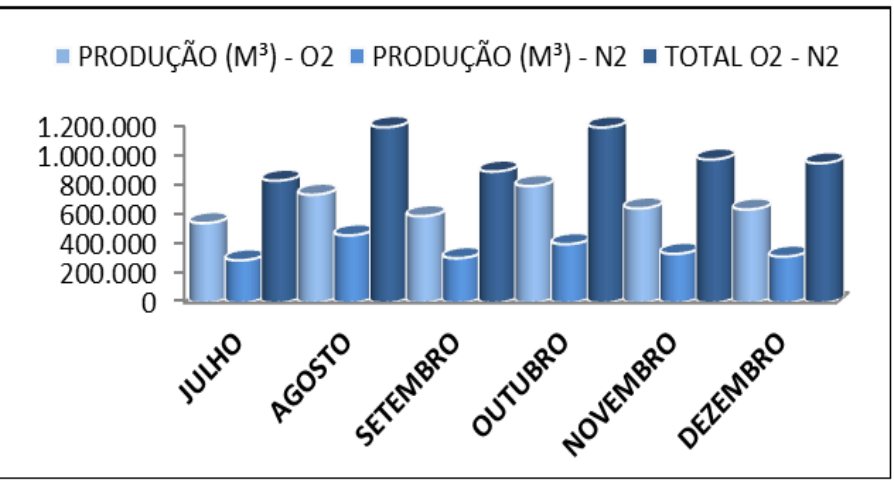

Figura 5. Produção $\mathrm{O}_{2}$ e $\mathrm{N}_{2}$ líquido $\left(\mathrm{m}^{3}\right)$-2 $2^{o}$ semestre de 2013. 
4.6.2 Comparativo semestral de perdas de produto em $\mathrm{m}^{3} \mathrm{de}$ oxigênio $\left(\mathrm{O}_{2}\right)$ e nitrogênio $\left(\mathrm{N}_{2}\right)$

A Figura 6 mostra que o $1^{\circ}$ semestre verificou-se perda significativa em $\mathrm{m}^{3}$ dos produtos $\mathrm{O}_{2}$ e $\mathrm{N}_{2}$ onde totalizaram $858.698 \mathrm{~m}^{3}$. Verificou-se que a maior perda se deu no mês de Maio com $166.459 \mathrm{~m}^{3}$ perdidos. Nota-se também que o gás $\mathrm{N}_{2}$ é o mais desperdiçado, somando $476.607 \mathrm{~m}^{3}$ durante o semestre.

$$
\square \text { PERDAS O2 }\left(\mathrm{M}^{3}\right) \square \operatorname{PERDAS} \mathrm{N} 2\left(\mathrm{M}^{3}\right) \square \text { PERDA TOTAL O2 - N2 }
$$

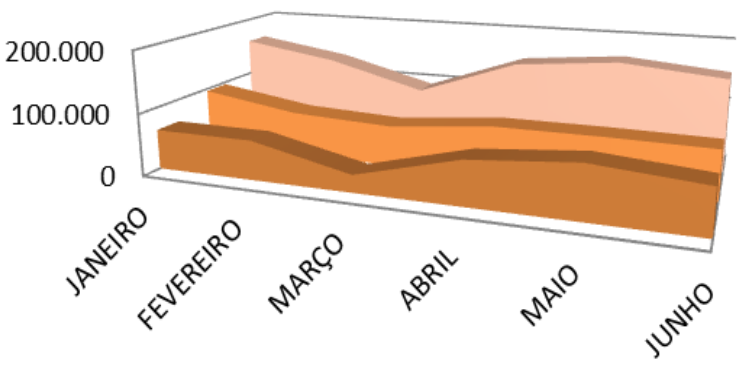

Figura 6. Perda mensal de $\mathrm{O}_{2}$ e $\mathrm{N}_{2}$ líquidos $\mathrm{m}^{3}-1^{\circ}$ Semestre de 2013.

Para o $2^{\circ}$ semestre, demonstrado na figura 7 a maior perda total dos gases foi calculada em $833.519 \mathrm{~m}^{3}$, onde a maior perda mensal ocorreu no mês de Agosto com $151.701 \mathrm{~m}^{3}$ desperdiçados. $\mathrm{O} \mathrm{N}_{2}$ continua sendo o gás que tem maior índice de perdas, totalizando durante o período $425.820 \mathrm{~m}^{3}$ de produto jogado fora. No comparativo semestral, nota-se que a maior perda em $\mathrm{m}^{3}$ se deu no $1^{\circ}$ semestre de 2013.

\section{—PERDAS O2 $\left(\mathrm{M}^{3}\right) \quad$ - PERDAS N2 $\left(\mathrm{M}^{3}\right) \quad \square$ PERDA TOTAL O2 - N2}

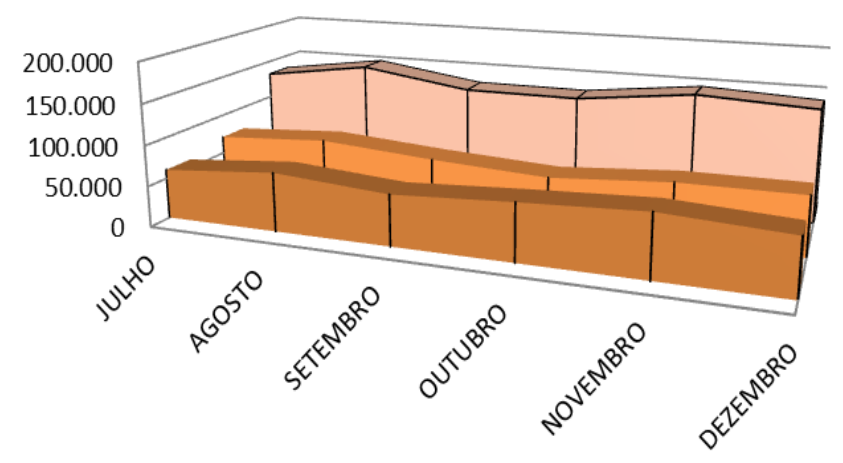

Figura 7. Perda mensal de $\mathrm{O}_{2}$ e $\mathrm{N}_{2}$ líquidos - $\mathrm{m}^{3}-2^{\circ}$ semestre de 2013.

\subsubsection{Comparativo semestral de perdas de produto em $\mathbf{R} \$$}

O gráfico da figura 8 mostra que durante o $1^{\circ}$ semestre de 2013, a perda em valor dos produtos $\mathrm{O}_{2}$ e $\mathrm{N}_{2}$, somou o equivalente a $\mathrm{R} \$ 389.249,58$. Verificou-se também, que no mês de Maio ocorreu a maior perda do período, o montante de $\mathrm{R} \$$ 74.818,68. O gás $\mathrm{N}_{2}$ foi o que apresentou a maior perda, somando o valor de $\mathrm{R} \$ 228.771,36$.

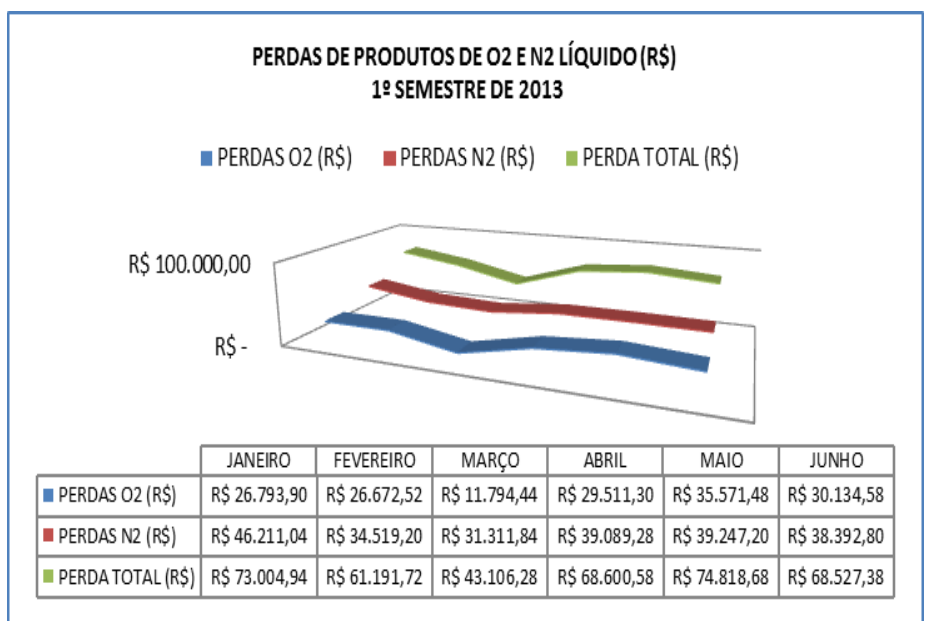

Figura 8. Perdas de produtos de $0_{2}$ e $\mathrm{N}_{2}$ líquidos $(\mathrm{R} \$) 1^{\circ}$ semestre de 2013.

Para o $2^{\circ}$ semestre, o gráfico da figura 9 mostra a perda total em valor para os gases totalizou a soma de $\mathrm{R} \$ 375.627,18$. Notou-se que a maior perda mensal foi identificada no mês de Agosto, com o valor de $\mathrm{R} \$ 68.495,46$. O gás $\mathrm{N}_{2}$ continua com maior índice de perdas no semestre, com o valor de $\mathrm{R} \$$ 204.393,60.

Mediante comparativo entre os semestres, nota-se que a maior perda se deu no $1^{\circ}$ semestre de 2013. É importante ressaltar que os produtos possuem preços de mercado diferentes, onde o oxigênio é vendido a $0,42 \mathrm{o} \mathrm{m}^{3}$ e o nitrogênio tem o valor de $0,48 \mathrm{o} \mathrm{m}^{3}$.

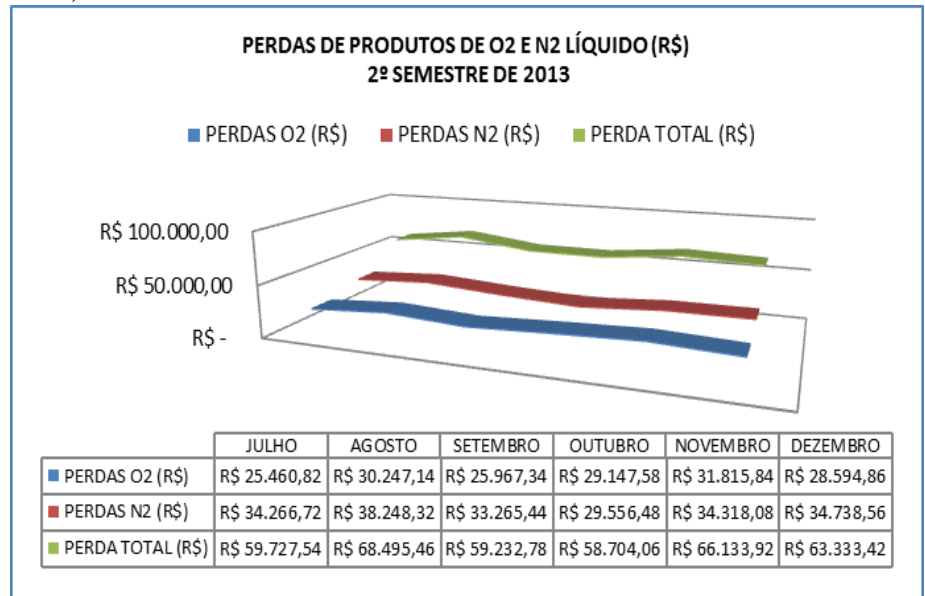

Figura 9. Perdas de produto $\mathrm{O}_{2}$ e $\mathrm{N}_{2}$ líquido (R\$) $2^{\circ}$ semestre de 2013.

\section{CONCLUSÕES}

Após, realizada toda a pesquisa e estudos referentes à perda de líquido criogênico durante o enchimento de carretas que atendem os clientes, podemos observar que o controle destas 
perdas decorre de uma série de fatores que vão desde físicos (troca de calor) até relacionados ao treinamento dos colaboradores envolvidos, desse modo, compreende-se que o sistema de enchimento adotado fica muito preso a falhas que por sinal geram grandes diferenças quando são totalizadas ao final de cada atividade. Os colaboradores por sinal se demonstram conscientes de tais perdas, mas que por falta de mais informações se retraem em dar alguma alternativa na solução da questão.

Uma resposta a esses questionamentos seria o investimento em equipamentos mais apropriados que não precisassem de tantos cuidados e também em treinamento aos colaboradores afim de que estes possam durante a atividade de enchimento saber como melhor solucionar qualquer eventualidade que possa ocorrer. Apesar da complexidade desse modelo produtivo é uma atividade lucrativa, pois atende uma grande gama de atividades relacionadas.

\section{Agradecimentos}

Ao Centro Universitário do Norte (UNINORTE), pelo apoio a realização desta pesquisa.

\section{Referências Bibliográficas}

[1] Azevedo Netto, J.M.; Fernandes, M.F.; Araújo, R.de; Ito, A.E. Manual de hidráulica. $8^{\mathrm{a}}$ ed. São Paulo: Edgard Blücker, 1998. $670 \mathrm{p}$.

[2] O. Khemis, R. Bessaih, M. Ait Ali, M.X. Francois. Measurement of heat transfers in cryogenic tank with several configurations. Appl Therm Eng, 24 (14-15) (2004), pp. 22332241.

[3] $\mathrm{Yu}, \mathrm{P} . \mathrm{D}$. Thermostating of cryogenic vessels with stored liquid vapour. Cryogenics 16 (4), p. 225-230. 1976.

[4] Scurlock, Ralph G., ed. (1993). História e as origens de Criogenia. Oxford, Clarendon Press.

[5] Criogênica Society of America, Cold Facts Newsletter, disponível a partir de www.cryogenicsociety.org.

CPAPMAX. Disponível em <https://www.oxigenio.com/oxi/dbc/educacional_oxigenio.htm>. Acesso em: 25 abril 2014.

[6] Barron, Randall. Sistemas criogênicos. Oxford, Oxford Press. 1985.

[7] Bianchi, José Carlos de Azambuja, Albrecht, Carlos Henrique, Maia, Daltamir Justino. Universo da química: volume único. São Paulo: FTD, 2005.

[8] Dalpiaz, Lucas de Medeiros. Análise do fornecimento dos produtos da destilação criogênica do ar. Monografia. Porto Alegre, 2010.
[9] Scurlock, Ralph G., ed. (1993). História e as origens de Criogenia. Oxford, Clarendon Press.

[10] Trindade, Iris da Silva. Proposição de Controle Metrológico na Medição de Líquidos Criogênicos. Dissertação de Mestrado-Centro Técnico Científico da PUC. Rio de Janeiro, Julho de 2003.

[11] R.F. Barron.Cryogenic technology.Ullmann's encyclopedia of industrial chemistry. Wiley-VCH Verlag $\mathrm{GmbH}$ and Co. KGaA (2000).

[12] Teixeira, Elizabeth. As três metodologias: acadêmica, da ciência e da pesquisa. $9^{\text {a }}$ ed. Petrópolis, RJ Vozes, 2012.

[13] Lakatos, Eva Maria, Marconi, Marina de Andrade. Fundamentos de metodologia científica. 7. ed. São Paulo: Atlas 2010a.

[14] Eva Maria, Marconi, Marina de Andrade. Metodologia do trabalho científico: procedimentos básicos, pesquisa bibliográfica, projeto e relatório, publicações e trabalhos científicos. 7. ed. 5.reimpr. São Paulo: Atlas 2010b.

National Institute of Standards and Technology. Disponível em <http://www.nist.gov/mml/acmd/cryogenics/aboutcryogenics.cf m>. Acesso em: 20 abril 2014.

[15] Polo Industrial de Manaus. Disponível em :<http://www.suframa.gov.br/publicacoes/site_pim/quimico.htm $>$. Acesso em: 20 abril 2014.

[16] Shachtman, Tom. Absolute Zero e da conquista de Fria. Boston, Houghton Mifflin Company. 1999.

[17] Weisend, John G. II, ed. (1998). Manual de Engenharia criogênico. Filadélfia, Taylor e Francis. 